\title{
De Prefectos a Mandatarios de la Nación. La violencia en la política peruana $(1829-1836)^{1}$
}

\author{
por \\ Víctor Peralta Ruiz \\ CSIC, Madrid \\ victor.peralta@cchs.csic.es
}

Bajo el primer gobierno del general Agustín Gamarra (1829-1833) se inició en el Perú la remodelación estatal o «dominación contemporánea mediante la administración». Consistió en el traslado al ejercicio estatal del modelo de patronazgo institucional puesto en práctica por Gamarra durante su desempeñó como prefecto del Cuzco. Sin embargo, este sistema administrativo de ideología conservadora sustentado en la oficialidad del ejército, las máximas autoridades departamentales y connotados personajes civiles fue insuficiente para dar estabilidad al país. Dos motivos lo explican: 1) las propias inseguridades del presidente hacia la lealtad de sus colaboradores politicos; 2) el enfrentamiento de Gamarra, primero, con los liberales que controlaban la Convención Nacional y la prensa, segundo, la pugna con el general Andrés de Santa Cruz por liderar la unificación de Perú y Bolivia en un solo Estado, y, tercero, la competencia con el coronel Felipe Santiago Salaverry por personificar la verdadera revolución conservadora «salvadora de la patria».

Palabras Clave: Administración estatal; patronazgo; conservadores; liberales; Perú; siglo XIX; Agustín Gamarra; Felipe Santiago Salaverry.

Este trabajo se adentra en el análisis de la coyuntura política que transcurrió entre el golpe de Estado contra el general José de La Mar el 7 de junio de 1829 y la derrota en Socabaya (Arequipa) de las fuerzas del general Felipe Santiago Salaverry frente al Ejército Unido peruano-boliviano del general Andrés de Santa Cruz el 7 de febrero de 1836 que dio lugar a la creación de la Confederación

\footnotetext{
${ }^{1}$ Investigación realizada dentro del proyecto I+D HAR2013-42563P.
} 
Perú-Boliviana. Entre 1829 y 1836 el Perú experimentó un prolongado clima de inestabilidad expresado en catorce revoluciones durante el primer gobierno del general Agustín Gamarra (1829-1833)², una revolución que derivó en dictadura, dos guerras civiles y una invasión extranjera bajo la presidencia del general Luis José de Orbegoso (1834-1836). Esta coyuntura fue el resultado de una pugna entre el republicanismo militar autoritario (Gamarra y Salaverry) y el republicanismo militar liberal (José de la Mar, Orbegoso y Domingo Nieto) ${ }^{3}$. Otras lecturas sobre esta coyuntura aluden a una pugna abierta entre dos legitimidades del poder sustentadas, de un lado, en la elección mediante sufragio $\mathrm{y}$, de otro, en el triunfo de una insurrección armada legalizada a posteriori por las urnas ${ }^{4}$; o subrayan la utilización de las constituciones como instrumentos políticos de batalla y de legitimación entre los políticos (en su mayoría militares) conservadores y liberales 5 . A estas interpretaciones se suman las investigaciones que han indagado en la participación de las guerrillas indígenas a favor de los conservadores en el escenario rural de las guerras civiles, en la actuación de los bandoleros y montoneros apoyando a los liberales en el convulso escenario limeño de 1834 y 1835 o, por último, en el apoyo de los artesanos a los políticos que asumieran el proteccionismo económico como bandera económica ${ }^{6}$.

Frente a las interpretaciones historiográficas mencionadas, este estudio propone una interpretación revisionista que se aleja de los tópicos que han perfilado a los militares como «caudillos» obsesionados por el poder y beneficiarios de la precariedad de las instituciones estatales. Se asume el cuestionamiento del concepto de «caudillo» como parte del rechazo a la interpretación holística del fracaso del Estado-nación en América Latina ${ }^{7}$. Se parte de que la caída del Antiguo Régimen, tanto en Europa como en América, obligó a experimentar con un nuevo modelo administrativo para fortalecer tempranamente el proceso de formación de las nuevas repúblicas. Esta «dominación contemporánea mediante la administración», tal como la define Lutz Raphael, supuso que en múltiples realidades las «modificaciones de la estructura interna y la justificación de los estados precipitar[a]n, en el plano político, en forma de enfrentamientos constitucionales, cambios de régimen y revoluciones» ${ }^{8}$. El caso del Perú no fue ajeno a esta constante histórica.

\footnotetext{
2 Basadre, 1961: 1, 321.

Mc Evoy, 2011: 783-786.

${ }^{4}$ Aljovín de Losada, 1995; 2000.

5 Sobrevilla, 2009: 115-116.

${ }^{6}$ Méndez, 2014: 298-316. Walker, 1990: 105-136. Gootenberg, 1997. García-Bryce, 2009.

7 Peralta e Irurozqui, 2000. Chocano, 2006: 7-21. Mc Evoy y Renique, 2010: 1, 36-38. Irurozqui, 2016 (en prensa).

${ }^{8}$ Raphael, 2008: 17.
} 
La innovación administrativa de ruptura con el modelo de gestión borbónico se inició bajo el Protectorado José de San Martín y prosiguió bajo la dictadura de Simón Bolívar, pero en ambos casos el experimento se truncó por la renuncia de ambos gobernantes extranjeros. El general Gamarra con su ideario nacionalista fue el verdadero impulsor de la primera dominación estatal republicana mediante la administración. De acuerdo con este planteamiento, en este trabajo se asumirá que el vaivén entre legalidad y revolución entre 1829 y 1836 fue el resultado de la apuesta por una forma de gobernar que, fundamentalmente, se sustentó en las lealtades políticas forjadas en torno a la potenciación de las autoridades políticas departamentales y provinciales como garantes del círculo de poder del gobernante ${ }^{9}$. Se propondrá que bajo un mecanismo de patronazgo y clientelismo, en su mayor parte articulado en torno a los prefectos y subprefectos, el general Gamarra auspició un incipiente proceso de institucionalización estatal desde una opción conservadora ${ }^{10}$. La misma implicaba privilegiar la preeminencia del poder ejecutivo sobre el legislativo, fortalecer el gobierno a partir de la preponderancia del ejército, impulsar el unitarismo como principio de organización interna y fomentar un nacionalismo autoritario para resolver el contencioso fronterizo con Colombia y Bolivia ${ }^{11}$. En este trabajo se sostendrá como hipótesis que por diversos motivos el vínculo de lealtad de los prefectos hacia el presidente fue insuficiente para forjar una dominación conservadora mediante la administración. Gamarra sucumbió a sus propias inseguridades respecto a la fortaleza de sus prefectos como clientes políticos y, además, creyó que tales lealtades resultaron fácilmente manipulables por sus dos enemigos políticos, el general Andrés de Santa Cruz desde Bolivia y el coronel Felipe Santiago Salaverry en Perú. Se sostendrá que las conspiraciones anti-gamarristas fueron en su mayoría invenciones que debilitaron más que fortalecieron al «general presidente». Del mismo modo, se asumirá que el proyecto dictatorial de Salaverry hizo suya la opción conservadora gamarrista, la radicalizó con el rescate de instituciones jurídicas pre-republicanas, como el Tribunal de la Acordada, y por eso fue comprensible que parte de la clientela política de Gamarra le apoyara.

\footnotetext{
9 Un estudio pionero sobre el papel político de las prefecturas en la primera década de la república en Sobrevilla, 2012: 161-183.

${ }_{10}$ «Gamarra establece, entre 1829 y 1833, un régimen cohesionado en toda la República, que se caracteriza por la lealtad de los prefectos departamentales», en Basadre, 1971: 1, 193.

${ }^{11}$ En cuanto a la política económica el gamarrismo sustentó el sistema mercantil colonial articulado en torno al eje Lima-Valparaíso, el cual se prolongó hasta mediados del siglo XIX, al respecto ver Gootenberg, 1989; 1997. Irurozqui y Lucena Giraldo, 2003.
} 
LOS ORÍGENES DEL GAMARRISMO (1825-1829)

Para la transformación de las intendencias borbónicas en prefecturas republicanas se adoptó el modelo unitario y centralizado. El 12 de febrero de 1821 el reglamento provisional del ejército libertador sancionado por el general San Martín en Huaura puso fin al sistema administrativo de intendencias y subdelegaciones que desarrolló el gobierno virreinal en la segunda mitad del siglo XVIII. Los cargos de intendente y subdelegados fueron reasignados, respectivamente, al presidente de departamento, al gobernador de partido y al teniente gobernador de los pueblos. Inicialmente, las atribuciones de los tres, en sus respectivos ámbitos de actuación, debían consistir en: proponer la creación de cuerpos de milicias, arreglar la economía interior y conocer en todas las causas civiles, criminales y de hacienda hasta que se constituyeran los tribunales de justicia y del tesoro público. Cuando con la independencia quedó establecido el Protectorado, fueron cuatro los departamentos sometidos a este nuevo sistema: Trujillo, Tarma, Huaylas y Lima. José de la Riva Agüero fue nombrado por San Martín como primer presidente de Lima el 4 de agosto de 1821. El hecho de que un presidente dependiera directamente del máximo responsable del gobierno protectoral permitió a Riva Agüero emprender un acto no contemplado entre sus facultades: destituir a un ministro. Aprovechando la obligada ausencia de San Martín, y apoyado por el ayuntamiento y una representación ciudadana, Riva Agüero lideró la caída y exilio del «despótico» ministro de Estado Bernardo Monteagudo en julio de 1822.

La Constitución liberal ${ }^{12}$ de 1823 creó el cargo de prefecto y le encomendó el gobierno superior político de los departamentos, así como sustituyó la nomenclatura de gobernadores por la de intendentes para el gobierno de las provincias ${ }^{13}$. Los prefectos quedaron bajo la inmediata dependencia del presidente de la República y sus atribuciones fueron constreñidas al orden y a la seguridad pública. Se les prohibió todo conocimiento judicial y su mandato se limitó a cuatro años. Además, se les impedía violar la seguridad personal pese a que se les autorizaba a encarcelar temporalmente a cualquier persona por motivos de tranquilidad pública hasta que un juez dictaminara sobre su libertad. Una novedad de esta constitución fue que cualquier exceso

${ }^{12}$ El liberalismo tuvo tres momentos históricos de hegemonía sobre la política, entre 1822 y 1823 durante la actuación del primer Congreso Constituyente, entre 1828 y 1829 bajo el gobierno del general José de La Mar y entre 1833 y 1835 con el gobierno del general Orbegoso. En estas coyunturas se sancionaron las tres constituciones liberales que otorgaron al poder legislativo el papel de refrendar y controlar la actuación del ejecutivo.

13 En las constituciones de 1826 y 1828 estos últimos pasaron definitivamente a denominarse como subprefectos. 
cometido por estas autoridades en el ejercicio de su empleo «produce acción popular», circunstancia que en la práctica no se activó y fue suprimida en las futuras constituciones. Durante la dictadura bolivariana el 2 de agosto de 1824 se decretó que fuesen los municipios los que propusieran al presidente a sus prefectos, intendentes y gobernadores, pero las múltiples dificultades en este procedimiento hicieron que la medida se suspendiese el 27 de mayo de 1826. En la Constitución de 1828 se confirmó a los prefectos y subprefectos la «intendencia económica de la hacienda departamental». En cambio, se les restringió cualquier tipo de injerencia en las elecciones populares y en la actuación de las juntas departamentales. Con relación a estas últimas, herederas de las diputaciones provinciales y cuyo funcionamiento comenzó en 1829, los prefectos de los departamentos del sur tendrían varios altercados en el uso de las atribuciones económicas y políticas ${ }^{14}$. Finalmente, en la Constitución liberal de 1834 se sumaron a las anteriores restricciones de los prefectos también la de impedir el funcionamiento de las municipalidades.

No menos significativo fue el procedimiento previo implantado por los congresistas liberales para que el presidente nombrara a las máximas autoridades políticas. En las cartas políticas de 1823 y 1828 se estableció que fuesen las juntas departamentales las que presentaran la lista de candidatos a prefectos, respectivamente, al Senado y al Ejecutivo, mientras que en la Constitución de 1834 se dispuso que la tarea de proponer tales candidaturas al presidente la asumiesen los colegios electorales de provincia. En la base de este principio estuvo el deseo de los liberales de que como los prefectos no eran elegidos mediante comicios al menos fueran pasasen por algún filtro «popular» para su nombramiento. Esta propuesta fue claramente asumida por el clérigo y político liberal Francisco Javier de Luna Pizarro al manifestar durante el debate sobre la reforma de la Constitución de 1823 que era de necesidad «que el poder arbitrario ahora ejercido por los prefectos como delegados de la autoridad suprema, deje de existir bajo un gobierno legal y constitucional $\rangle^{15}$. Pero esta medida apenas se aplicó durante el primer gobierno de Gamarra.

Al margen de lo dispuesto en las constituciones, la orden más significativa con relación a la actuación de las máximas autoridades departamentales, provinciales y distritales fue el reglamento de sus atribuciones promulgado por el presidente Gamarra el 25 de febrero de 1830 de acuerdo con el artículo constitucional 138. La redacción de este dispositivo legal, que constó de 53 artículos, estuvo marcada por el conflicto que el Perú mantenía con Bolivia. De ahí que además de confirmarles su preeminencia en la recaudación de

\footnotetext{
14 Rivera Serna, 1964: 3-18.

15 Citado en Zas Fritz Burga, 1998: 38.
} 
los fondos públicos y la jefatura de las milicias y de las fuerzas de policía locales en tiempos de tranquilidad y de conmoción interna, se consignase que los prefectos «si aconteciese invasión súbita de enemigo exterior en los territorios de fronteras determinarán, requiriendo al efecto al comandante de armas, que sea repelido y perseguido por la fuerza pública existente en ellos» ${ }^{16}$. Esta última atribución permitió a Gamarra utilizar legalmente a los prefectos de su mayor confianza como garantes de su régimen durante su accidentado primer mandato constitucional. En otras palabras, el referido reglamento de 1830 fue, junto con el drástico reordenamiento que dispuso en los altos mandos del ejército, el soporte del aparato conservador que este mandatario pretendió constituir para garantizar su gestión política y, de paso, instaurar su modelo de Estado. Por último, el 31 de agosto de 1831 Gamarra sancionó una nueva ley complementaria de atribuciones para prefectos y subprefectos al persistir los conflictos entre ambas autoridades y entre estas y las comandancias generales, en el ámbito militar, y las juntas departamentales, en cuanto a iniciativas en obras públicas.

Para comprender el obsesivo interés del general cuzqueño por legislar sobre las prefecturas hay que remontarse a su época como presidente y comandante general del Cuzco, cargo que comenzó a ejercer por nombramiento de Simón Bolívar poco después de la victoria de Ayacucho. Gamarra asumió en su persona las funciones que detentaban hasta ese momento tanto el Regente de la Audiencia como el Presidente-Intendente. Por ello el ceremonial que la corporación municipal puso en práctica para festejar su entrada en la capital cuzqueña fue el mismo que se utilizó para las fenecidas autoridades coloniales ${ }^{17}$. La entrada oficial se produjo el 25 de diciembre de 1824 «en medio del más grande y bullicioso regocijo del pueblo. Arcos triunfales, tapicería en los balcones y flores por doquier adornaron las calles de su recorrido» ${ }^{18}$. Sus primeras medidas consistieron en abolir la Audiencia y el Cabildo perpetuo y establecer en su lugar la Corte Superior de Justicia y un municipio integrado por autoridades nombradas por elección popular. Simultáneamente, ordenó que su título de presidente cambiase al de prefecto en aplicación de la constitución. En cuanto al nombramiento de los intendentes de provincia, luego nombrados subprefectos, Gamarra optó por mantener en el cargo a varios funcionarios coloniales que habían desempeñado cargos administrativos y/o de justicia en tiempos del último virrey. Tales fueron los casos del intendente del Cercado,

\footnotetext{
${ }^{16}$ Santos Quiroz, 1832: 305.

17 Sobre el ritual del poder en los inicios de la república como acto comunicativo individual y corporativo, ver Ortemberg, 2014

18 Villanueva Urteaga, 1981: 9.
} 
Agustín Rosel, y del intendente de Quispicanchis, José Mariano Ugarte. De nuevo nombramiento fue el caso del intendente de Calca, Mariano García Pumacahua, por su condición de hijo del cacique indio que había liderado la revolución de 1814. Importante fue la designación del comerciante Juan Ángel Bujanda como intendente de Urubamba. Este fue poco después nombrado por Bolívar como coronel del regimiento de infantería de milicias cívicas de Calca, Urubamba y Paucartambo. Bujanda iba a convertirse en el paradigma del subprefecto políticamente leal a Gamarra por vínculos clientelares y de padrinazgo, por eso en 1829 ascendió a prefecto al inaugurarse el primer gobierno de su protector.

El departamento del Cuzco durante la época en que Gamarra fue prefecto disfrutó de una coyuntura de calma política y social. Esta estabilidad se explicaba porque Gamarra conformó una red estable de autoridades políticas en la que «los funcionarios medios tales como los subprefectos y los dirigentes de la milicia eran más importantes que los oficiales militares y las guerrillas» ${ }^{19}$. En el caso de los jefes de milicia, que en varios casos también fueron subprefectos, su papel fue clave en el fortalecimiento del gamarrismo cuzqueño. Muchos de ellos tras probar su eficacia como organizadores de milicias fueron promovidos por Gamarra a los altos mandos del ejército para revalidar esa lealtad en los campos de batalla. Charles Walker destaca como ejemplo a Agustín Rosel, subprefecto y jefe de milicias entre 1825 y 1834, y luego en 1835 combatiente por el gamarrismo contra el gobierno del general Orbegoso $^{20}$.

En las once provincias cuzqueñas los subprefectos mantuvieron la prerrogativa en el ámbito militar de los antiguos subdelegados. Eso explica que, a pesar de la demanda de las jefaturas militares, fueran ellos quienes asumieran el reclutamiento de soldados y milicianos, al tiempo que vigilaban a los opositores y se convertían en propagandistas de la causa del prefecto. Es decir, el sistema político se montó sobre una forma de gobierno local parecido al régimen centralizado de las intendencias borbónicas. Esta transición institucional sin convulsiones fue facilitada por la práctica inexistencia de clanes políticos patriotas en la ciudad que demandaran la recompensa de los empleos públicos. A diferencia de lo ocurrido en Lima en la época del Protectorado, los servidores cuzqueños del rey acataron sin conflicto su transformación en administradores republicanos. Relata Walker que los políticos en Lima denunciaron a Gamarra ante Bolívar por incorporar a demasiados realistas «capitulados» como subprefectos. Aquel justificó su decisión en que de sus

\footnotetext{
19 Walker, 1999: 175.

20 Ibidem: 178.
} 
once subprefectos cinco habían luchado en la revolución de 1814 y el resto en posteriores batallas por la independencia ${ }^{21}$.

La preservación por parte de la naciente República de los antiguos sistemas impositivos, como fue el caso del tributo indígena, facilitó que la dominación administrativa de Gamarra fomentada a partir de las lealtades prefecturales tuviera relativo éxito. El cobro del tributo en el caso del departamento cuzqueño suponía casi el $77 \%$ de sus ingresos desde los tiempos virreinales. Para mantener ese ritmo recaudatorio Gamarra logró contener los deseos de Bolívar de liberalizar el campo con medidas encaminadas a distribuir las tierras entre los indígenas, crear impuestos prediales y acabar con las comunidades. Al poco tiempo que el Libertador renunció a sus poderes dictatoriales y abandonó el país, Gamarra ayudado por sus subprefectos pudo implementar un sistema clientelar en torno al cobro del tributo que benefició a las comunidades, a las que se protegió en su condición de «clases menesterosas», a los recaudadores de origen mestizo e indio, a quienes se premió legal y subrepticiamente por cumplir con las cobranzas tasadas, y hasta a los indígenas «forasteros», a los que se entregó tierras ${ }^{22}$.

Cuando el general La Mar asumió la presidencia en 1827, Gamarra transfirió la prefectura al general Bujanda y asumió el mando del Ejército del Sur bajo una ideología que combinaba el republicanismo conservador, el antibolivarismo y la xenofobia nacionalista. En esas circunstancias se produjo en la capital boliviana de Chuquisaca el 18 de abril de 1828 un intento de golpe de Estado contra el presidente Antonio José de Sucre -último representante del proyecto bolivariano de crear una federación de los Andes- en el que éste resultó herido. Gamarra aprovechó la circunstancia para intervenir con su ejército en Bolivia sin la autorización del gobierno de La Mar ni del Congreso. El hecho es que, alegando que con su invasión garantizaba al vecino país no caer en la anarquía, impuso al presidente interino José María Pérez de Urdininea el tratado de Piquiza del 6 de julio de 1828, por el que Bolivia admitía la renuncia de Sucre, la salida del ejército colombiano de su territorio y la reunión de una Asamblea Nacional para nombrar un nuevo mandatario. Paradójicamente, el general Andrés de Santa Cruz apoyó la actuación de Gamarra al felicitar por carta al presidente La Mar por haber «arrojado al astuto e insidioso Sucre, enemigo el más obstinado de la libertad e integridad de la república peruana ${ }^{23}$.

\footnotetext{
${ }^{21}$ Ibidem: 175.

${ }^{22}$ Peralta Ruiz, 1991: 42. Peralta e Irurozqui, 2000.

${ }^{23}$ Manifiesto [1828]: 365.
} 
Esta intervención en la política boliviana, en la que se impuso la breve presidencia «tutelada» del general Pedro Blanco, fue uno de los motivos que condujo en 1829 a la Gran Colombia de Bolívar a entrar en guerra con el Perú. El revés peruano ante el ejército colombiano de Sucre en Tarqui (27 de febrero de 1829), cuya responsabilidad compartieron La Mar y Gamarra, condujo al día siguiente a la firma del convenio Girón por el que el ejército peruano aceptaba replegarse a Piura. Fue en esas circunstancias que se fraguó el golpe de Estado contra La Mar en el que actuaron como líderes Gamarra y el general Antonio Gutiérrez de la Fuente, ex prefecto de Arequipa. El 2 de junio de 1829, dos días antes de producirse el golpe, Gamarra escribió a Gutiérrez de la Fuente, quien se hallaba con sus tropas en Lima, que «Ud. y yo somos los que debemos salvar la patria o dejar de existir. En U. fío y es mi única esperanza... No olvide U. que todo el objeto es dividirnos: cuidado con los malvados: divididos caemos, precisamente» ${ }^{24}$. Esta frase es muy elocuente del tipo de acuerdo político fraguado entre dos personajes que basaron su alianza en un sistema de reciprocidad y confianza mutua. El objetivo sólo se alcanzaría si la amistad política forjada entre ambos no era erosionada por otras personalidades empeñadas con sus maquinaciones en dividirles. Luego de la deposición y expatriación de La Mar en Piura al igual que la de su vicepresidente Salazar y Baquíjano en Lima, Gutiérrez de la Fuente asumió de manos del Cabildo la jefatura suprema provisional el 5 de junio de 1829 y convocó al congreso para legitimar el nuevo gobierno en el que participaría.

\section{LAS CONSPIRACIONES CONTRA EL PRIMER GOBIERNO DEL «GENERAL PRESIDENTE»}

Fue durante su breve interinato presidencial que Gutiérrez de la Fuente experimentó el supuesto primer intento de intervención del general Santa Cruz en la política peruana desde su condición de presidente de Bolivia ${ }^{25}$. En esta conspiración habrían participado como líderes altos mandos miliares y numerosos prefectos y subprefectos del sur andino, designados por La Mar, y que tras ser éste exiliado acordaron cuestionar la legalidad de lo actuado por los dos generales golpistas. Según esta versión Santa Cruz en su marcha de Chile hacia Bolivia para asumir la presidencia habría creado con varias autoridades peruanas de los departamentos sureños una logia política «a fin de arribar a la Presidencia del Perú o conseguir el desmembramiento de los antiguos de-

\footnotetext{
${ }^{24}$ Gutiérrez de la Fuente, 1831: 20.

${ }^{25}$ Para una biografía actualizada sobre Santa Cruz ver Sobrevilla, 2011.
} 
partamentos de Arequipa, Cuzco y Puno, para anexarlos a Bolivia» ${ }^{26}$. Adeptos del plan crucista habrían sido el prefecto de Puno, coronel Rufino Macedo, el prefecto de Arequipa, coronel Juan Francisco Reyes, y el comandante general de Arequipa, general Manuel Martínez de Aparicio. Se desconoce el grado de adhesión a esta causa del prefecto de Cuzco, Vicente León, al ser este destituido por el cabildo el 12 junio y reemplazado por el coronel Bujanda, quien de inmediato reafirmó su lealtad a Gamarra.

El 8 de agosto en Arequipa un grupo de jóvenes militares, encabezado por el coronel Manuel Amat y León, se rebelaron y procedieron a destituir y apresar al comandante militar Martínez de Aparicio y al prefecto Reyes bajo el cargo de planear la separación de Arequipa y su fusión con Bolivia. El 12 de agosto en Puno, al tener conocimiento de este hecho, el prefecto Macedo hizo pública una proclama que sólo se publicó en el periódico oficial boliviano El Iris de la Paz. En la misma arengaba a los puneños a tomar las armas para defender su autoridad ante el rumor de que los militares rebeldes de Arequipa se estaban movilizando para destituirle. En todo momento Macedo rechazó que actuara con un propósito secesionista: «para corroborar tamaño atentado se nos ha imputado la falsedad de que este departamento trataba de romper la integridad territorial y unirse a la república de Bolivia» ${ }^{27}$. La única medida tomada en Bolivia había sido movilizar al ejército a la frontera bajo las órdenes del coronel José Ballivián, cuyas acciones se habían hecho en coordinación con el prefecto. Además, el gobierno crucista rechazó las acusaciones de los periódicos arequipeños El Acento de la Justicia y Arequipa Libre de que «el extranjero» Santa Cruz estaba detrás de la actuación de Macedo, enfatizándose categóricamente que «el Presidente de Bolivia no ha querido ni quiere mandar al Perú» ${ }^{28}$.

Haya sido cierta o no la conjura crucista de Macedo, el general Gamarra procuró recuperar la lealtad del prefecto puneño apelando a sus sentimientos patrióticos y usando un discurso xenófobo. En su carta al prefecto del 27 de agosto de 1829, dos días antes de ser nombrado presidente, daba por creíble la versión que le había proporcionado Gutiérrez de la Fuente acerca del complot secesionista en Puno. Gamarra reconocía ante Macedo ser partidario como Santa Cruz de la fusión de ambos países pero bajo la denominación de «nación peruana, no la boliviana». Justificó esa postura en que el Perú históricamente nunca dependió de Bolivia pero en cambio «Bolivia siempre ha sido del Perú»». Por último, se consideró artífice de la independencia definitiva de aquel país

\footnotetext{
${ }^{26}$ Herrera Alarcón, 1961: 13.

27 El Iris de la Paz, 22 de agosto de 1829.

${ }^{28}$ Ibidem, 5 de septiembre de 1829.
} 
con su invasión de 1828 porque «sin el Perú, Bolivia estaría respetando y aún adorando a los negros de Colombia, que trasladaron desde el Orinoco sus galpones guineos para manejarlos como a unos degradados colonos» ${ }^{29}$. A pesar de este intento de reconciliación, Macedo prosiguió su rebeldía contra el nuevo gobierno hasta que, al ver fracasadas sus negociaciones, se exilió en Bolivia a principios de noviembre de 1829.

La elección constitucional de Gamarra y Gutiérrez de la Fuente, respectivamente, como presidente y vicepresidente de la República, se produjo el 31 de agosto de 1829. Por primera vez dos ex autoridades prefecturales asumían el poder a partir de su alianza. La remodelación de la esfera política por parte del nuevo mandatario para preservarse en el poder consideró como un instrumento clave de gobierno la urdimbre del patronazgo. Bajo este concepto se comprende la promoción de obligaciones vinculantes y recíprocas con un exclusivo patrón. Esto quiere decir que Gamarra, situado en la cúspide de un sistema piramidal, se convirtió en el único dador legítimo de cargos, premios y favores para una amplia base de personajes adscritos a su séquito político. Este principio basó su perdurabilidad en evitar que se potenciaran otros liderazgos que pusieran en real o potencial peligro los privilegios del único patrón. A modo de un personaje provisto de un poder monista y mayestático, Gamarra se consideró como depositario exclusivo de la «soberanía del pueblo» $\mathrm{y}$, por ello, único legitimado para escoger a las máximas autoridades subalternas. Tal modelo fue aplicado a la designación de los encargados de las siete prefecturas de la República (Puno, Arequipa, Ayacucho, Cuzco, Junín, La Libertad y Lima) y reprodujo la selectividad que Gamarra dispuso en su época como máxima autoridad cuzqueña. Es decir, en tales cargos seleccionó a aquellos militares y civiles de probada fidelidad con el «general presidente», que habían combatido a su lado en las campañas de 1821 a 1829 o que fueron eficientes colaboradores durante su gestión en la prefectura. También en la selección se valoró que los escogidos para los cargos fuesen «poco afectos» al ex mandatario La Mar, al Congreso y a los militares y/o civiles liberales. Otro requisito adicional para ser elegido consistió en que estas autoridades departamentales refrenaran su ambición personal o la subordinaran a la que exclusivamente alentaba su jefe. Se comprende que dentro de esta lógica del ejercicio del poder Gamarra introdujese en el reglamento de febrero de 1830 un artículo en el que prohibía el entendimiento político entre los prefectos ya que los mismos «son independientes unos de otros».

Los prefectos gamarristas acumularon un poder político mayor que los ministros, los congresistas, los vocales de las juntas departamentales, los alcaldes

${ }^{29}$ Herrera Alarcón, 1961: 32. 
o los comandantes militares. En su ámbito territorial representaron ceremonialmente la «viva imagen» del presidente y sus potestades gubernativas, además del control del orden y la tranquilidad pública, se proyectaron a los ámbitos de la hacienda, las milicias, la concesión de empleos y la justicia. Pero tal poder fue cuestionado por aquellos que consideraban que las prerrogativas de tales autoridades les llevaban a actuar al margen de lo legal y a cometer excesos. Tal fue el motivo de la rebelión que estalló en el Cuzco el 26 de agosto de 1830 en contra del prefecto Bujanda, quien fue apresado. El coronel Gregorio Escobedo lideró el movimiento militar y sus objetivos los expuso en la sala consistorial del ayuntamiento del siguiente modo:

los jefes de la obra, y algunos ciudadanos habían representado que se hallaba el vecindario oprimido por la fuerza: que ella había constituido al señor Bujanda en la Prefectura con infracción y desprecio de la ley, que previene sea aprobado uno de los presupuestos por la muy honorable Junta Departamental, en cuya clase no estaba dicho Prefecto: que exigiendo la observancia de la Constitución se hallaba también sin cumplimiento, y que por último desprendiéndose de aquella opresión, pedía el uso y libertad de sus derechos, a fin de que la próxima Legislatura pueda según los votos de estos departamentos constituir un Gobierno federal o el más análogo ${ }^{30}$.

Aunque se ha sostenido que detrás del levantamiento cuzqueño de 1830 estuvo el general Santa Cruz y su plan secesionista del sur peruano, lo cierto es que lo que Escobedo adujo como motivo de su alzamiento fue un abuso de autoridad y una infracción constitucional: la confirmación presidencial de Bujanda en un puesto al que había llegado mediante la destitución de su antecesor y sin ser revalidado por los órganos legislativos. Todo indica que el objetivo final de los rebeldes era adaptar el departamento al federalismo tal como lo propugnaban en el país los liberales más radicales ${ }^{31}$. Su plan también consistía en convencer al prefecto de Arequipa a que procediese del mismo modo. Bajo presión de Escobedo, los miembros del ayuntamiento y de la Junta Departamental designaron como nuevo prefecto al coronel Juan Tomás Moscoso, asumiendo interinamente Escobedo ese cargo. Pero la revuelta concluyó inesperadamente al día siguiente cuando un grupo de militares fieles a Gamarra, liderados por el coronel Bartolomé Arregui, se enfrentaron con las armas a los rebeldes, rescataron a Bujanda de su cautiverio y le devolvieron el mando prefectural. A pesar de que no estar entre sus prerrogativas dictar sentencia contra los sediciosos, Bujanda organizó un consejo de oficiales que juzgó sumariamente a cuatro de los cabecillas de la rebelión y les fusiló. En-

\footnotetext{
30 Odriozola, 1877, X: 162.

31 Basadre, 1929, I: 193.
} 
tre estos no estuvo Escobedo, quien fue castigado con su exilio a Bolivia. Se desconoce la reacción oficial boliviana ante este hecho porque El Iris de la Paz dejó de circular durante esas fechas para que la imprenta gubernamental sacase en exclusividad los códigos de Santa Cruz.

Otra convulsión política suscitada en Lima condujo el 16 de abril de 1831 a la destitución del vicepresidente Gutiérrez de la Fuente por instancias del prefecto coronel Juan Bautista Eléspuru. El destierro del general arequipeño suscitó el fin de su alianza política con Gamarra que apenas se había prolongado un año. El motivo de la caída en desgracia del vicepresidente se explica en su emulación de la actuación prebendataria que exclusivamente para sí se había reservado el presidente. En efecto, aprovechando que Gamarra en septiembre de 1830 había partido al Cuzco apenas supo de la rebelión de Escobedo, Gutiérrez de la Fuente asumió que podía adoptar iniciativas sin ningún tipo de consulta mientras controlara el mando supremo provisional. Entre las mismas destacaron: la violación del correo con el propósito de vigilar a los partidarios de su enemigo personal, el general Riva Agüero, la anulación por decreto de una ley legislativa que prohibía la introducción de tocuyo y harinas por el puerto de El Callao, la arbitraria clausura de la junta departamental bajo la acusación de perturbar el orden público y, finalmente, el nombramiento como edecán del capitán Vivanco, quien poco antes había criticado a Gamarra. Esto último junto con la autorización vicepresidencial que permitió el retorno del clérigo liberal Luna Pizarro de su destierro en Bolivia, llevaron a que tanto la esposa del presidente, Francisca Zubiaga, como el prefecto Eléspuru sospecharan que Gutiérrez de la Fuente tramaba dar un golpe de Estado contra Gamarra en connivencia con los liberales y el general Santa Cruz.

Al margen de si fue cierto que Gutiérrez de la Fuente pretendiese derrocar al mandatario, su error a ojos de sus correligionarios residió en adoptar decisiones que fueron sopesadas por los fieles de Gamarra como una violación de la alianza política fraguada en 1829. Así lo expresó Eléspuru al resaltar, en su Contestación al manifiesto del general Gutiérrez de la Fuente editado en su destierro, su deslealtad con el «general presidente». Se trataba de

...dar a conocer a los extraños el necio y criminal empeño de La Fuente, en obscurecer la verdad y ocultar sus negras tramas para sobreponerse al general Gamarra, cuyo influjo y generosidad le ascendieron al elevado puesto de que abusó en mengua de su protector y daño de la Nación ${ }^{32}$.

32 Contestación que da el prefecto del departamento de la capital de Lima al manifiesto publicado por el general La Fuente, reproducido en Odriozola, 1877, X: 408. 
En varios pasajes de su folleto Eléspuru añadía frases propias de un lenguaje político afín a un patronazgo unilateralmente quebrado como era el intento del vicepresidente de «menguar la reputación de su protector», su deseo de convertir «esta comisión en su provecho personal» o su propósito de constituirse en «mandatario cómplice de las injusticias que le granjeasen prosélitos». La inmediata caída en desgracia y exilio en Chile de Gutiérrez de la Fuente, con el tácito respaldo de Gamarra a la acción emprendida por el prefecto limeño, no fue sino el final de un experimento en que una amistad política se quebraba por las dobleces de un personaje que creía que podía actuar libremente como inconsulto alter ego del mandatario ausente.

La desaparición temporal del escenario político de Gutiérrez de la Fuente no devolvió la tranquilidad al primer gobierno de Gamarra. Dicha coyuntura estaría dominada por el crónico diferendo diplomático con Bolivia, en el que los mandatarios de ambas naciones se culpaban mutuamente del estado de tensión en la frontera y, en el caso de Gamarra, de las revoluciones que periódicamente enfrentaba. Además, la profundización de la crisis económica peruana enfrentaba a las elites de los departamentos del norte, cuyo proteccionismo económico las unía a Chile, con los propietarios de los departamentos del sur, librecambistas que deseaban la unificación con Bolivia para recuperar el vínculo mercantil de la época virreinal ${ }^{33}$. Esta partición de intereses económicos alimentaba también la contienda parlamentaria y periodística entre el conservadurismo gamarrista y el liberalismo lunapizarrista, ya que dentro del gamarrismo hubo quienes simpatizaron con los librecambistas y entre los lunapizarristas los hubo defensores del proteccionismo ${ }^{34}$. La inestabilidad del primer gamarrismo creció aún más por la polémica en torno a la oficialidad del ejército resultante de la ley de reforma militar promulgada en diciembre de 1829. La aplicación de esta normativa, paradójicamente, supuso el retiro voluntario o coercitivo de un alto porcentaje de oficiales nacionales en su mayoría opuestos a Gamarra o no pertenecientes a sus grupos de adeptos. De ello resultó que el mando militar quedó dominado por un sector identificado como «los suizos», constituido en su mayor por oficiales españoles capitulados de la época de Ayacucho y de otras nacionalidades americanas. Los liberales encontraron así otro motivo para atacar a Gamarra: el de favorecer a los «extranjeros» en su afán de controlar el ejército.

La personalidad de Gamarra fue quizás autoritaria pero su gobierno transmitió la sensación de carecer de autoridad para contener a sus adversarios. De poco sirvieron la persecución de enemigos políticos, como el diputado liberal Félix Iguain, y los castigos de prisión a militares acusados de conspiradores,

\footnotetext{
33 Gootenberg, 1991: 273-308.

34 Gootenberg, 1989.
} 
caso del coronel Castilla, para devolver la sensación de orden. El fusilamiento por orden del propio Gamarra del capitán cuzqueño Felipe Rosell el 19 de marzo de 1832 por intento de asesinato del mandatario se sustentó en una delación no probada y no aumentó la popularidad de aquel. Por conspirador y supuesto espía de Santa Cruz el general Blas Cerdeña, nacido en Gran Canarias y residente en Arequipa, fue apresado en Lima el 11 de noviembre de 1832 y trasladado a Trujillo a cumplir su condena ${ }^{35}$. Su liberación se produjo bajo el gobierno del general Orbegoso, lo que confirma que su pérdida de libertad se debió a sus simpatías con los liberales. Asimismo, ninguna de las represalias aplicadas por el «general presidente» amedrentó al gran conspirador anti-gamarrista de la época: el coronel Felipe Santiago Salaverry. La histórica enemistad entre Gamarra y Salaverry respondía en realidad al fracaso del primero en incorporar al segundo en su red de patronazgo. Durante la guerra con Colombia Salaverry fue ayudante del Estado Mayor general de La Mar y combatió en Tarqui. No aprobó el golpe de Estado liderado por Gamarra a pesar de que le premiase con su ascenso a teniente coronel. Lejos de apoyar al nuevo mandatario, Salaverry solicitó y obtuvo su licencia militar en febrero de 1831, pero Gamarra le convenció para que asumiese el cargo de subprefecto y comandante general de Tacna. El presidente creyó haber alejado el peligro de que Salaverry fuese utilizado por los partidarios de La Mar al concederle poder político e incluso ser su padrino de boda en julio de 1832. Pero éste no tardó en decepcionarle al asumir su «no pertenencia a partido alguno» y al renunciar a la subprefectura a fines de 1832 en su deseo de dedicarse a la agricultura en Lima. Como indica su biógrafo Bilbao «esta marcha precipitada y sin miramiento a la tenacidad de Gamarra para conservarle en Tacna, no fue bien mirada por la autoridad $»^{36}$.

La represalia del gamarrismo se fraguó cuando Salaverry fue apresado por formar parte de una hipotética conspiración tramada en marzo de 1833 por los generales Gutiérrez de la Fuente y Riva Agüero para derrocar al presidente. Los ataques de la prensa gamarrista a Salaverry fueron contestados por éste desde su prisión a través del periódico La Patria en Duelo. Al persistir en su rebeldía, Gamarra dispuso su confinamiento junto con otros cuatro militares en la casi inaccesible provincia de Amazonas en julio de 1833. Esta decisión fue desacertada porque dicha región selvática, como lo advirtió el subprefecto Castro, carecía de milicias y/o fuerzas del orden para vigilar a los militares confinados en el poblado de Huallaga. Por eso fue relativamente fácil a Salaverry y sus compañeros confinados obtener el apoyo de ciertos grupos étnicos y rebelarse contra el subprefecto, destituirle y ocupar la capital, Chachapoyas,

\footnotetext{
35 Exposición, 1833.

36 Bilbao, 1853: 104.
} 
el 13 de septiembre de 1833. Al reconocer su error, Gamarra dispuso que los rebeldes fueran combatidos por una compañía militar al mando del prefecto y comandante general de La Libertad, general José María Raygada. Al llegar a Chachapoyas constató que los propios conspiradores habían traicionado y apresado a Salaverry. Aunque la crisis parecía solucionada, el 26 de octubre de 1833 la tropa de Raygada se rebeló contra él cuando hicieron una parada en Cajamarca y proclamó a Salaverry como líder de la revolución. El prefecto atribuyó dicho levantamiento tanto a la indolencia del subprefecto cajamarquino como a la traición de los mandos militares de sus compañías. Fiel al discurso de las autoridades gamarristas sureñas precisó que el objetivo de la revolución había sido el de federar el departamento o "constituirlo una República de que fuese Presidente el que sea más aspirante» ${ }^{37}$. Sin embargo, tácitamente se desprende de este comentario que las autoridades políticas y militares en el norte del país, a excepción de Raygada, no eran piezas fundamentales de la red gamarrista. El prefecto Raygada no sólo fue destituido sin oposición alguna, sino que, a continuación, Salaverry nombró nuevas autoridades políticas para Cajamarca y Trujillo que aceptaron la oferta sin ninguna objeción. En este último caso, el prefecto de facto Lizarzaburu se encargó de armar la milicia trujillana que junto con las compañías rebeldes debía contener a las tropas gubernamentales enviadas desde Lima al mando del coronel Francisco Vidal.

A pesar de reconocer su inferioridad numérica, Salaverry no aceptó la propuesta de Vidal de rendir a su ejército porque, en sus palabras, «habría traicionado las esperanzas del pueblo que le apoyaba para emanciparse del despotismo de Gamarra» ${ }^{38}$. Los rebeldes fueron derrotados en la contienda de Moche y Salaverry huyó a Lambayeque. El gobierno recuperó Trujillo el 20 de noviembre de 1833 y Vidal poco después apresó a Salaverry. A pesar de contar con la autorización de Gamarra para fusilarle, Vidal optó por exiliar a Salaverry a Ecuador. Sin embargo, este consiguió fugarse del navío que le conducía a su destierro y reorganizó en Piura sus fuerzas para iniciar una nueva revuelta. Fue en esas circunstancias que se produjo un cambio de la coyuntura política al producirse el relevo presidencial de Gamarra por Orbegoso por decisión de la Convención Nacional el 21 de diciembre de 1833. Bajo este nuevo gobierno y como resultado del estallido de la guerra civil del año siguiente, los papeles se trocaron para Vidal y Salaverry y en esta nueva oportunidad este último fue el vencedor definitivo. Con su pronunciamiento de Trujillo de febrero de 1834 a favor del gobierno de Orbegoso, Salaverry transitoriamente calmó su secreta ambición de hacerse con el poder para «salvar a la patria».

\footnotetext{
${ }^{37}$ José María Raygada, 1833: VIII.

${ }^{38}$ Bilbao, 1853: 125.
} 
El general Orbegoso fue el segundo prefecto que llegaba al poder por disposición del Legislativo. A diferencia de Gamarra en Cuzco, su gestión como máxima autoridad del departamento de La Libertad por disposición de Bolívar no le condujo a constituir un entramado clientelar con las autoridades políticas provinciales bajo su mando. Durante este tiempo, más bien, el interés de Orbegoso se concentró en hacer visitas periódicas «para formar una completa estadística de todos los lugares y distritos, observar las costumbres de sus habitantes, promover su ilustración ${ }^{39}$. Entre 1824 y 1828 , de forma interrumpida Orbegoso ejerció la prefectura y la comandancia general. Cuenta en sus Memorias que renunció a dicho cargo en dos ocasiones (1826 y 1827) por haber sido elegido diputado y que, una vez cumplidos ambos encargos, retornó a la prefectura. Esta experiencia como legislador explica que, al contrario que Gamarra, Orbegoso (al igual que otros militares como Domingo Nieto o Bernardo Soffía) se vinculara con los políticos liberales bajo el patronazgo político de Luna Pizarro. Por ello y como muestra de lealtad al presidente La Mar, renunció de modo definitivo como prefecto en 1828 para asumir la Comandancia General de Caballería durante la guerra con Colombia. El golpe de Estado de 1829 explica la enemistad de Orbegoso con Gamarra y Gutiérrez de la Fuente y, en señal de protesta, aquel obtuvo su retiro militar para dedicarse a administrar su hacienda. Pero a instancias de Luna Pizarro en julio de 1833 retornó a la política como diputado por Huamachuco a la Convención Nacional y, meses después, fue nombrado mandatario provisorio.

Los liberales optaron por la elección de Orbegoso y descartaron al candidato apoyado por el «general presidente» que era el general Pedro Bermúdez, quien desempeñó el cargo de ministro de Guerra y Marina. Este militar era para Gamarra la única garantía de continuidad de su modo de hacer política. Por eso tras la derrota de Bermúdez, el presidente saliente cambió de opinión y consideró que la elección de Orbegoso había sido hecha por una instancia legislativa cuya única facultad era redactar la Constitución. Gamarra aseveró que frente a su candidato que «tenía la preferencia de los pueblos y del ejército», la Convención optó por «un candidato que a su nulidad intelectual, militar y política, reuniese la calidad de enemigo mío» ${ }^{40}$. Este fue el pretexto aducido por el general cuzqueño para apoyar la revolución contra Orbegoso perpetrada en Lima por los batallones del general Bermúdez el 3 de enero de 1834, con la que se inició una guerra civil. Gamarra además confesó al

\footnotetext{
${ }^{39}$ Memorias, 1939: 30-44.

40 Manifestación, 1835: 6.
} 
comandante Camilo Carrillo que «poniendo al frente de esta administración bajo el nombre de jefe supremo provisorio a mi compadre el general Bermúdez [la salvación de la patria estaba garantizada]» ${ }^{41}$. La guerra civil se prolongó hasta el 24 de abril de 1835 cuando en el paraje de Maquinhuayo (Jauja) las tropas bermudistas comandadas por el coronel Rufino Echenique a pesar de su superioridad, inesperadamente, depusieron las armas y reconocieron a Orbegoso (hecho conocido como el «abrazo de Maquinhuayo»). Este inusitado final de la contienda supuso el colapso definitivo del sistema de patronazgo montado por Gamarra durante su primer mandato al exiliarse en Bolivia. En los siguientes párrafos se destacará las maniobras del gamarrismo para conservar infructuosamente el poder.

El general Bermúdez en su proclama del 4 de enero de 1834 resaltó que su único objetivo era que el nuevo mandatario fuese el ganador de unas nuevas elecciones. Por eso al día siguiente mediante decreto convocó a los colegios electorales de provincias para que procedieran a la elección del presidente y vicepresidente. Seguidamente, dispuso que el Congreso Extraordinario se reuniera el 1 de mayo para calificar las actas electorales y proclamar al candidato vencedor. Este procedimiento no sólo garantizaba a Bermúdez su legitimación en el poder, sino que eliminaba a los convencionales de la escena política. Entre tanto, Gamarra como comandante general del ejército procedió a sitiar el fuerte Real Felipe de El Callao donde se había refugiado Orbegoso. Pero la suerte se tornó adversa para Bermúdez cuando una parte de su ejército comenzó a desertar al conocerse el pronunciamiento de Arequipa y otras ciudades a favor de Orbegoso. La situación para los golpistas se volvió insostenible el 28 de enero una vez que la población limeña asedió a las tropas de Bermúdez ante los rumores de que iban a saquear la capital antes de abandonarla. Basadre ha definido el acontecimiento como la primera lucha de «la multitud contra el ejército». Las tropas bermudistas ante el descontrol social se replegaron en dirección a la sierra central, mientras que Orbegoso, una vez restablecida su autoridad, organizó su ejército para combatir a las tropas leales a Bermúdez y Gamarra. La guerra civil se escenificó en tres frentes: el sur por el control de Arequipa, el centro en torno a la ocupación del valle de Jauja en la sierra y el norte donde la lucha se proyectó a la toma de Trujillo. En ese escenario, la Convención concedió poderes extraordinarios a Orbegoso y, al reconocer la inferioridad de las fuerzas que apoyaban al presidente, el 18 de abril aprobó que en caso de necesidad extrema este solicitara ayuda militar al presidente boliviano Santa Cruz «con el exclusivo objeto de terminar la guerra civil» ${ }^{42}$.

\footnotetext{
41 Tauro, 1952: 250.

42 Távara, 1951: 171.
} 
Los prefectos de Gamarra legalmente dejaron de serlo en cuanto este dejó la presidencia. La mayoría estaba ejerciendo el cargo de modo provisional cuando la guerra civil estalló y algunos de ellos no dudaron en convertirse en baluartes del gamarrismo. La lealtad de estas autoridades hacía su protector alzado en armas se puso a prueba por vez primera. Tal fue el caso del general José María Frías en Ayacucho. Al estallar la crisis política este prefecto interino procedió de modo arbitrario y no dio a conocer a la población el nombramiento de Orbegoso. Por el contrario, en relación con el pronunciamiento de Bermúdez, Frías «se conmovió de gozo, fue dado a reconocer como tal jefe supremo por un bando publicado con la solemnidad debida ${ }^{43}$. A través del periódico oficial La Oliva de Ayacucho se convenció a la población y a las instituciones representativas que el presidente nombrado por la Convención era un intruso. Además varios folletos fueron auspiciados por Frías «ridiculizando la administración de S.E. el general Orbegoso, y se aseguraba con énfasis que la guerra en que nos íbamos a ver envueltos sería la lucha entre el régimen constitucional y la anarquía». Con esta expresión Frías asumía el lenguaje político de Gamarra sobre la inconstitucionalidad de lo obrado por la Convención. En una proclama del 29 de enero dicho prefecto comunicó a los ayacuchanos que «vuestros diputados solo obtuvieron poderes para reformar la Constitución; pero [...] se erigieron en omnipotentes y se convirtieron desde luego en vuestros más encarnizados enemigos ${ }^{44}$. Lo más significativo es que no hubo discrepancia local con el juicio emitido por Frías. En el transcurso de la campaña los gamarristas se identificaron como «ejército vengadores de la ley», mientras que el «ejército constitucional» de Orbegoso les calificó de «tropas disidentes». Frías comandó un batallón rebelde en la contienda de Huaylacucho (17 de abril) y cayó muerto al ser atravesado por una lanza procedente de las tropas constitucionales. A pesar del deceso del prefecto, las tropas bermudistas se hicieron con el triunfo aunque una semana después la guerra terminó abruptamente en Maquinhuayo. Tras la pacificación, los partidarios de Gamarra en Ayacucho fueron procesados por las nuevas autoridades políticas y a todos se les identificó grotescamente como «las sombras de Frías» ${ }^{45}$.

El prefecto interino cuzqueño Bujanda tuvo una reacción contradictoria al conocer los sucesos de Lima. En su proclama al departamento del 21 de enero sorpresivamente asumió la neutralidad en nombre de la defensa del orden y de la integridad de la República, de ahí que expresara que «ni condenamos ni

\footnotetext{
43 Garrido, 1835: 9.

44 El Iris de La Paz, 2 de marzo de 1834.

45 Garrido, 1835: 14.
} 
justificamos, aún, el movimiento de la capital de Lima». Pero tres días después varió su postura al conocer el pronunciamiento del 13 de enero en Arequipa a favor de Orbegoso. Con el respaldo del prefecto y a la vez alcalde Masías, el general Domingo Nieto al asumir la comandancia general instó a los arequipeños a la lucha armada contra un gobierno militar que «ha suplantado al de la razón y de la ley» ${ }^{46}$. En opinión de Bujanda esa reacción de los mandos arequipeños iba a desembocar en la anarquía y en la desintegración de la República tal como lo había temido el ex presidente Gamarra. Por medio de un bando, Bujanda se posicionó del lado de Bermúdez y «con los movimientos de la Capital de la República, por disgustantes que ellos parezcan, con tal que sean adoptados por la mayoría de los pueblos y no tiendan a la destrucción del país» ${ }^{47}$. Esta autoridad estableció «un cordón de línea» con Arequipa que supuso la interrupción de la correspondencia, prohibió cualquier discusión pública relacionada con lo ocurrido en dicho departamento y penalizó las conversaciones «sediciosas contra el Gobierno y actual orden de cosas». La posición de Bujanda se fortaleció al ser secundado en su apoyo a Bermúdez por el prefecto de Puno, el coronel Miguel San Román, aunque sus motivos políticos fueran distintos a los del clan gamarrista ${ }^{48}$. Ambos se prepararon para atacar Arequipa y ante tal amenaza el general Nieto, comandante general de la plaza, «pidió, en enero 15, a Santa Cruz, presidente de Bolivia, el auxilio de 2.000 hombres» ${ }^{49}$ sin lograr su objetivo. San Román en una carta dirigida al comandante Camilo Carrillo le instaba a unirse a su causa porque «la conducta de este general [Nieto] a mi concepto, prepara la anarquía en el país, para que su resultado sea la invasión del extranjero [Santa Cruz] ${ }^{50}$. La respuesta de Carrillo, publicada por el diario oficial boliviano, rechazaba la oferta de San Román de enfrentar la anarquía porque «no me persuado todavía que haya Peruano que hable este lenguaje». Finalmente, el coronel Eléspuru, quién dejó de ser prefecto de Lima antes de la revolución, se puso a las órdenes de San Román porque «la voluntad de Gamarra era para él una ley sagrada y así, desde que éste como general en jefe tomó aquella determinación, no disgustó a Eléspuru seguir en el Sud con el título de segundo general del ejército» ${ }^{51}$.

46 Valdivia, 1956: 31.

47 El Iris de La Paz, 23 de febrero de 1834.

48 En el periódico El Restaurador de Arequipa del 24 de febrero de 1834 se «reproduce una carta de San Román al general Frías, del 13 de enero de 1834, en la cual se hace evidente que la decisión y acuerdo de sublevarse estaba vigente ya en el mes de diciembre de 1833 » (Mendiburu, 1963: 274).

49 Basadre y Chocano, 1953: 13.

50 El Iris de La Paz, 13 de marzo de 1834.

51 Mendiburu, 1963: 85. 
Como fiel reflejo de la división del país en dos bandos, el norte por Orbegoso y el sur por Bermúdez con la excepción de Arequipa, las prefecturas de La Libertad, bajo mando del coronel Francisco Vidal, y de Junín, presidida por el coronel Francisco Quirós, optaron por sumarse a la capital en la defensa de la legalidad personificada por la Convención. De un lado, Vidal, sobre quien recaían sospechas de simpatizar con Gamarra, se vio precisado a esclarecer ante la opinión pública su conducta de fidelidad al gobierno de Lima el 4 de febrero. La justificó «para evitar en el departamento los inevitables males que podrían sobrevenir por el choque de opiniones $\rangle^{52}$. La revolución que días después hizo Salaverry contra Vidal acabó con la presencia política de este militar con el beneplácito de Orbegoso. De otro lado, Quirós fue más claro que Vidal en resaltar la ideología a la que se plegaban en la contienda: «este departamento es decidido por la ley, y que sus sentimientos liberales no serán jamás sometidos a la sugestión de los disidentes $\rangle^{53}$. A estas autoridades se sumó de modo inesperado el general Gutiérrez de la Fuente, a quien Orbegoso no sólo permitió retornar de su exilio en Chile sino que le entregó el mando de las tropas constitucionales en la campaña del centro con el que aquel confiaba vengar mediante las armas su defenestración por Gamarra.

La actuación del gobierno de Orbegoso contra los prefectos que se rebelaron a su mandato fue contundente tanto en el transcurso de la guerra civil como una vez concluida la misma. El 20 de febrero los generales Frías y Eléspuru fueron dados de baja del ejército junto con Gamarra y Bermúdez. Este castigo se hizo extensivo a Bujanda y San Román tal como relató Orbegoso ante la Convención del siguiente modo:

\footnotetext{
igual suerte ha cabido a otros jefes colaboradores incansables de la revolución, los que no eran acreedores a consideración alguna: el coronel San Román caudillo de las tropas de Cangallo, el coronel Bujanda, el mismo que tuvo ánimo bastante para escribir a Gamarra que en pronunciarse por el orden más hacía que sujetarse a la ley de la necesidad ${ }^{54}$.
}

También se criminalizó al ex prefecto de La Libertad, el general Raygada, a quien se expatrió a Centroamérica por ser «corruptor del general Vidal» ${ }^{55}$, siendo el general Gutiérrez de la Fuente deportado al mismo destino. Fue acusado por Orbegoso de mofarse de su autoridad y pretender, durante la campaña del centro, su reconocimiento como legítimo jefe de gobierno en su

\footnotetext{
${ }^{52}$ El Iris de La Paz, 27 de marzo de 1834.

53 Idem.

${ }^{54}$ Razón motivada, 1834: 9.

${ }_{55}$ Idem.
} 
condición de último vicepresidente. Por último, el presidente creó una junta de purificación militar para declarar «sujetos a juicio» a todos los jefes y oficiales que habían apoyado a los dos líderes de la revolución y a los prefectos sediciosos. Todas estas medidas se tomaron con el propósito de extirpar al partido gamarrista de la escena política, objetivo que se logró hasta el 23 de febrero de 1835 en que tuvo lugar en Lima la revolución del general Salaverry. Aprovechando que Orbegoso se hallaba en campaña militar por el sur del país, Salaverry, hasta entonces director de la Guardia Nacional, hizo huir de la capital al presidente accidental Salazar y Baquíjano. El motivo aducido por el militar revolucionario para proclamarse jefe supremo de la república fue el de acabar con la «acefalia política» que, a su juicio, representaba Orbegoso así como con la corrupción en las futuras elecciones presidenciales.

La reacción inmediata de las prefecturas ante el pronunciamiento de Salaverry rompió el tradicional enfrentamiento histórico entre departamentos norteños contra sureños. Apoyaron la revolución las autoridades político-militares de La Libertad (coronel Juan G. Torrico), Ayacucho (coronel Pío Tristán) y Cuzco (coronel Manuel Lopera), en tanto que se opusieron a ella Arequipa (general Blas Cerdeña) y Junín (general Necochea). El caso de Puno ejemplifica el desconcierto que conllevaba tomar partido por uno u otro contrincante. Su prefecto, el coronel Ramón Castilla, se opuso a Salaverry el 9 de marzo pero al unirse varios batallones puneños a la revolución presentó su renuncia al cargo. Una asamblea departamental proclamó como nuevo prefecto a Miguel de Urbina y declaró el 15 de marzo al departamento «libre e independiente de toda autoridad que le sea extraña» ${ }^{56}$. El 8 de abril Puno desconoció a Orbegoso, pero no dio su apoyo a Salaverry y suspendió sus relaciones con Arequipa y Cuzco a la espera de forzar una federación entre los departamentos del sur. Esta situación se complicó aún más con el retorno al Cuzco de Gamarra en mayo, tras su acuerdo con Santa Cruz en Bolivia para federar los departamentos del sur en un nuevo Estado. Pero el 24 de junio Orbegoso se adelantó a aquel en la plasmación de esa iniciativa a cambio de que el presidente boliviano asumiera el mando supremo en la derrota militar de Salaverry. Al fracasar su alianza con Santa Cruz, Gamarra se alió con Salaverry y le reconoció como jefe supremo, plegándose a su decreto de hacer la «guerra a muerte» al Ejército Unido peruano-boliviano. Tras ser derrotado Gamarra por Santa Cruz en Yanacocha (13 de agosto de 1835), Salaverry rompió su alianza con el ex presidente y le exilió a Costa Rica. Con Gamarra también fue desterrado el coronel Eléspuru, quien había sido nombrado prefecto del Cuzco y jefe del

${ }^{56}$ El Iris de La Paz, 5 de abril de 1835. 
ejército del Sur durante la coalición entre Gamarra y Salaverry ${ }^{57}$. En el exilio Eléspuru continuó siendo el más importante colaborador de Gamarra entre los que habían sido sus prefectos. Eléspuru se alistó en el ejército restaurador chileno-peruano que combatió a la Confederación y murió en la batalla de Yungay (21 de enero de 1839).

A diferencia de la lealtad de Eléspuru hacia Gamarra, el coronel Bujanda adquirió un protagonismo clave dentro de la dictadura de Salaverry y sin haberlo acordado con su antiguo benefactor político. Por una carta cursada el 3 de diciembre de 1834 a Nieto, Orbegoso confirmaba que vigilaba a Bujanda en Lima y sospechaba de su actuación como agente de «una alianza entre el partido de La Fuente y el de Gamarra» ${ }^{58}$. Debió ser una sorpresa inesperada para él que tras la revolución, Salaverry nombrara a Bujanda comandante general del departamento de Lima, cargo equivalente al de prefecto. La actuación más polémica del militar cuzqueño se produjo en abril de 1835 cuando Salaverry, al partir con su ejército con dirección al norte para combatir al general Nieto, le delegó el poder supremo en la capital. Bujanda se valió del Tribunal de la Acordada, una instancia judicial de la época colonial repuesta por Salaverry, para juzgar a los montoneros, los bandoleros y todos los enemigos del régimen. Pero también sujetó a ese tribunal a los gobernadores de distrito, los jueces, los inspectores de barrio, los serenos y los empleados de policía. Por último, decidió que las penas de la Acordada eran inapelables y restableció la horca como castigo infamante, tormento que Salaverry tuvo que derogar el 26 de mayo. En Bolivia, donde Santa Cruz había promulgado un nuevo código penal, se calificó a la Acordada como una aberración jurídica de la dictadura que retrataba a su mentor:

Bujanda, con un establecimiento reprobado por la opinión y las luces del siglo, hace reaparecer las formas inquisitoriales, el tribunal de sangre que hizo estremecer a la España para ahogar la libertad y sistemar la esclavitud ${ }^{59}$.

Pero el ascenso de Bujanda prosiguió y en mayo fue nombrado ministro de Guerra y Marina. Al producirse el acuerdo entre Orbegoso y Santa Cruz, Salaverry comisionó a Bujanda y al escritor Felipe Pardo y Aliaga a viajar al Cuzco para firmar la alianza con Gamarra. El tratado fue firmado el 27 de julio de 1835 y como resultado del mismo Bujanda reactivó su relación clientelar con Gamarra, sumándose a su ejército como oficial con el desagra-

\footnotetext{
57 Mendiburu, 1963: 86.

58 Mc Evoy y Rénique, 2010: 1, 260.

59 El Iris de La Paz, 31 de mayo de 1835.
} 
do de Salaverry. Por eso tras la derrota de Yanacocha, Bujanda también fue desterrado a Costa Rica por el dictador. Apenas establecida la Confederación Perú-Boliviana, Gamarra desde su nuevo refugio en Cuenca (Ecuador) intentó infructuosamente restablecer su amistad política con el general Gutiérrez de la Fuente usando al ex prefecto como intermediario. En carta del 8 de septiembre de 1836 le aseveraba: «recibirá U. por medio del Coronel Bujanda las demostraciones más francas de amistad; él dará a U. un abrazo tierno y quedará sólidamente establecido el nuevo modo de nuestras relaciones, y empezaremos a trabajar» ${ }^{60}$. Pero la muerte por veneno de Bujanda en 1837 impidió que continuara siendo una pieza clave en a red de poder del primer gamarrismo.

\section{CONCLUSIONES}

Tres prefectos llegaron a ser presidentes al comenzar la República: Riva Agüero, Gamarra y Orbegoso, a los cuales se puede añadir Gutiérrez de la Fuente que ejerció la presidencia interina por breve tiempo. De todos ellos el único que concibió un proyecto político de corte conservador para «salvar la patria» fue Gamarra. Consistió en ejercer el poder adoptando una relación de patronazgo con la alta oficialidad del ejército, las máximas autoridades políticas departamentales y personalidades civiles de ideología conservadora. La lealtad clientelar de los prefectos fue clave para el sostenimiento de este sistema institucional semejante a una «dominación mediante la administración». Pero este proyecto naufragó a lo largo del primer gobierno gamarrista. Las catorce conspiraciones políticas entre 1829 y 1833 -algunas fabricadas por las autoridades gamarristas para reprimir a los liberales-, demuestran que el régimen del «general presidente» fracasó por proyectar éste, subjetivamente, un permanente temor hacia los adversarios tanto fuera como dentro de su entorno clientelar. El primer caso lo ejemplificó el general Salaverry, a quien Gamarra infructuosamente procuró convertir en su ahijado político, al convertirse en un enemigo interno del gobierno con sus tres revoluciones. El último caso lo representó con su caída en desgracia y destierro el vicepresidente Gutiérrez de la Fuente en 1831. El otro enemigo de la «dominación administrativa» gamarrista fue el presidente boliviano Santa Cruz, a quien, por el contrario, los liberales peruanos vieron como un aliado político. El fracaso de la guerra civil de 1834-35, resultado del golpe de Estado contra Orbegoso por parte del favorito de Gamarra, el general Bermúdez, condujo a la desarticulación

${ }^{60}$ Tauro, 1952: 265. 
del sistema gamarrista. Si bien Salaverry al dar el golpe de Estado contra Orbegoso en febrero de 1835 intentó forjar una nueva dominación administrativa conservadora, pero esta vez forjada alrededor del ejército, su derrota en febrero de 1836 ante el Ejército Unido peruano-boliviano puso fin a su experimento marcial.

En febrero de 1839 el general Gamarra contribuyó al descalabro de la Confederación Perú-Boliviana ${ }^{61}$ y se convirtió en presidente provisional de Perú. En su condición de Gran Mariscal Restaurador convocó un congreso constituyente en Huancayo que promulgó la cuarta constitución de la república y permitió su segunda elección presidencial. En la Carta se contemplaba que los prefectos fueran directamente nombrados por el presidente sin el obstáculo de ternas confeccionadas previamente por instancia representativa alguna. De nuevo, un régimen de gobierno interior de la República sometido a su exclusiva potestad política era básico para restablecer el proyecto estatal que no pudo ejecutar entre 1829 y 1833 . Pero para su segundo mandato constitucional, Gamarra ya no contaba con sus antiguas clientelas militares porque casi todas las autoridades departamentales de su primer gobierno habían fallecido. Así, aún con nuevos nombres en el ejército y en las prefecturas, Gamarra se propuso restablecer su sistema de dominación administrativa conservadora. $\mathrm{Su}$ error fue vincular, como en 1828, el afianzamiento de su prestigio con la invasión de Bolivia aprovechando su aparente desgobierno tras la caída del general Santa $\mathrm{Cruz}^{62}$. Su muerte en el campo de batalla de Ingavi el 18 de noviembre de 1841 acabó con su deseo de desarrollar un sistema político mayestático que, probablemente, hubiera cimentado un partido conservador controlado por los mandos militares.

\section{BibLIOGRAFÍA}

Aldana, Susana, "La confederación peruano-boliviana. Los últimos sueños bolivarianos y los primeros de integración", Guillermo Lohman Villena (ed.), Homenaje a Félix Denegri Luna, Lima, PUCP, 2000.

Aljovín de Losada, Cristóbal, "Violencia y legitimidad: las revoluciones entre 1827 y 1841", Revista Histórica, XXXVIII (Lima, 1995): 257-277.

Aljovín de Losada, Cristóbal, Caudillos y constituciones, Perú: 1821-1845, Lima, Instituto Riva Agüero y Fondo de Cultura Económica, 2000.

\footnotetext{
${ }^{61}$ Aldana, 2000.

62 Irurozqui, 2013: 17-46.
} 
Basadre y Chocano, Modesto, Diez años de historia política del Perú (1834-1844), Lima, Editorial Huascarán, 1953.

Basadre, Jorge, La iniciación de la república, Lima, Librería Científica y Francesa F. y E. Rosay, 1929.

Basadre, Jorge, Historia de la república del Perú, Lima, Editorial Peruamérica, 1963.

Basadre, Jorge, Introducción a las bases documentales para la historia de la república del Perú con algunas reflexiones, Lima, P. L. Villanueva, 1971.

Bilbao, Manuel, Historia del general Salaverry, Lima, Imprenta del Correo, 1853.

Chocano, Magdalena, "Caudillismo y militarismo en la tradición interpretativa de la historiografía peruana”, Iberoamericana América Latina-España-Portugal, 6/22 (Frankfurt, 2006): 7-21.

Exposición, que presenta a sus conciudadanos el general de división Blas Cerdeña, sobre su prisión y posteriores consecuencias, dimanadas de la conducta del Supremo Gobierno en la capital de la república en 11 de noviembre de 1832, Trujillo, Imprenta del Sol, 1833.

García-Bryce, Iñigo, Republica con ciudadanos. Los artesanos de Lima, 1821-1879, Lima, IEP, 2009.

Garrido, Andrés, Ensayo sobre la conducta del ciudadano Andrés Garrido, en los últimos acontecimientos que han aflijido a su patria, Lima, Imprenta de la Gaceta por José Masias, 1835.

Glave, Luis Miguel, La república instalada. Formación nacional y prensa en el Cuzco, 1825-1839, Lima, IEP-IFEA, 2004.

Gootenberg, Paul, Between Silver and Guano: Commercial Policy and the State in Postindependence Peru, Princeton, Princeton University Press, 1989.

Gootenberg, Paul, "North-South: Trade Policy, Regionalism, and Caudillismo in PostIndependence Peru", Journal of Latin American Studies, 23/2 (Londres, 1991): 273-308.

Gootenberg, Paul, Caudillos y comerciantes. La formación económica del estado peruano, 1820-1860, Lima, IEP-CBC, 1997.

Gutiérrez de la Fuente, Antonio, Manifiesto del general La Fuente, Santiago de Chile, Imprenta Republicana, 1831.

Herrera Alarcón, Dante F., Rebeliones que intentaron desmembrar el sur del Perú, Lima, Imprenta del Colegio Militar Leoncio Prado, 1961.

Irurozqui, Marta y Lucena Giraldo, Manuel, "Lima versus Valparaiso. El balance de poder en el área andina”, Juan Maiguashca (coord.), Historia de América Andina, vol. 5, Quito, Universidad Andina Simón Bolivar, 2003: 419-458. 
Irurozqui, Marta, "De Yungay a Ingavi. El derecho a la revolución y la ciudadanía armada en Bolivia, 1839-1842", Revista de Investigaciones Bolivianas/Bolivian Research Review, 10/1 (La Paz, 2013): 17-46.

Irurozqui, Marta, “Ciudadanía armada versus caudillismo. Tres historias bolivianas sobre violencia y ley constitucional, 1841-1875", Marta Bonaudo y Nuria Tabanera (eds.) Historias de las culturas políticas en América Latina, Madrid, Marcial Pons Historia y Universidad Autónoma de Madrid, 2016 (en prensa).

José María Raygada ante la nación peruana, Trujillo, Imprenta del Sol por Paredes, 1833.

Manifestación que hace el general Gamarra al Congreso y a toda la nación peruana sobre los acontecimientos que lo obligaron a defenderse y a defender la tranquilidad pública bajo las órdenes del general de brigada D. Pedro Bermúdez, Cuzco, Imprenta Libre por Evaristo González, 1835.

Manifiesto del general Urdininea refutando las calumniosas injurias con que le ataca el Gran Mariscal de Ayacucho en su Mensaje presentado al Congreso extraordinario de Bolivia, Chuquisaca, Imprenta Boliviana, [1828].

Mc Evoy, Carmen y Rénique, José Luis, Soldados de la república. Guerra, correspondencia y memoria en el Perú (1830-1844), Lima, Congreso del Perú e Instituto Riva Agüero, 2010.

Mc Evoy, Carmen, "No una sino muchas repúblicas: una aproximación a las bases teóricas del republicanismo peruano, 1821-1834", Revista de Indias, LXXI/253 (Madrid, 2011): 759-792.

Memorias del Gran Mariscal Don Luis José de Orbegoso, Lima, Gil S.A. Editores, 1939.

Méndez, Cecilia, La república plebeya. Huanta y la formación del Estado peruano, 1820-1850, Lima, Instituto de Estudios Peruanos, 2014.

Mendiburu, Manuel de, Biografías de generales republicanos, Lima, Talleres Gráficos de la Editorial Lumen, 1963.

Odriozola, Manuel de, Documentos históricos del Perú, Lima, Imprenta del Estado, 1877.

Ortemberg, Pablo, Rituales del poder en Lima (1735-1828). De la monarquía a la república, Lima, Pontifica Universidad Católica del Perú, 2014.

Peralta Ruiz, Víctor, En pos del tributo. Burocracia estatal, elite regional y comunidades indígenas en el Cusco rural (1826-1854), Cusco, Centro Bartolomé de las Casas, 1991.

Peralta Ruiz, Víctor y Irurozqui, Marta, "Por la Fusión, la Concordia y el Unitarismo”. Estado y caudillismo en Bolivia, 1826-1880, Madrid, CSIC, 2000.

Raphael, Lutz, Ley y orden. Dominación mediante la administración en el siglo XIX, Madrid, Siglo XXI de España Editores, 2008. 
Razón motivada que el presidente provisional da a la Convención Nacional sobre el uso que ha hecho de las facultades extraordinarias que se le confirieron en 17 de febrero, y que devolvió en 11 de junio, Lima, Imprenta del Constitucional, 1834.

Rivera Serna, Raúl, "Las juntas departamentales durante el primer gobierno del Mariscal don Agustín Gamarra", Boletín de la Biblioteca Nacional, 31-32 (Lima, 1964): 3-18.

Santos Quiroz, Mariano, Colección de leyes, decretos y órdenes publicadas en el Perú. Desde su Independencia en el año de 1821, hasta el 31 de diciembre de 1830, Lima, Imprenta de José Masías, 1832.

Sobrevilla, Natalia, "Batallas por la legitimidad. Constitucionalismo y conflicto político en el Perú del siglo XIX (1812-1860)", Revista de Indias, LXIX/246 (Madrid, 2009): 101-128.

Sobrevilla, Natalia, The Caudillo of the Andes. Andrés de Santa Cruz, Cambridge, Cambridge University Press, 2011.

Sobrevilla, Natalia, "Ciudadanos en armas: el ejército y la creación del Estado, Perú (1821-1861)", Juan Carlos Caravaglia, Juan Pro Ruiz y Eduardo Zimmermann (eds.), Las fuerzas de guerra en la construcción del Estado: América Latina, Rosario, Prohistoria Ediciones, 2012: 161-183.

Tauro, Alberto (ed.), Epistolario del Gran Mariscal Agustín Gamarra, Lima, Universidad Nacional Mayor de San Marcos, 1952.

Távara, Santiago, Historia de los partidos, Lima, Editorial Huascarán, 1951.

Valdivia, Juan Gualberto, Las revoluciones de Arequipa, Arequipa, Editorial El Deber, 1956.

Villanueva Urteaga, Horacio, Gamarra y la iniciación republicana en el Cuzco, Lima, Banco de los Andes, 1981.

Walker, Charles F., "Montoneros, bandoleros, malhechores: criminalidad y política en las primeras décadas republicanas", Carlos Aguirre y Charles Walker (eds.), Bandoleros, abigeos y montoneros: criminalidad y violencia en el Perú, siglos XVIII-XX, Lima, IAA, 1990: 105-136.

Walker, Charles F., De Tupac Amaru a Gamarra. Cusco y la formación del Perú republicano 1780-1840, Cusco, Centro Bartolomé de las Casas, 1999.

Zas Fritz Burga, Johnny, La descentralización ficticia. Perú 1821-1998, Lima, Universidad del Pacífico, 1998.

Fecha de recepción: 17 de junio de 2015.

Fecha de aceptación: 14 de septiembre de 2015. 


\section{From Prefects to Heads of State. Violence in Peruvian Politics (1829-1836)}

Under Agustin Gamarra's first administration (1829-1833) a state reform or "contemporary domination by the administration" began. This consisted in transferring the institutional patronage model, which was put into practice by Gamarra while he was prefect of Cuzco, to a state practice. However, this administrative system of conservative ideology supported by military officials, top departmental authorities and distinguished civilians was not enough to provide stability for the country. There are two reasons behind this: 1) the president's own insecurities regarding the loyalty of his political collaborators; 2) Gamarra's clash with, first, the liberals who controlled the National Convention and the press, second, the struggle with General Andrés de Santa Cruz to lead the unification of Peru and Bolivia to become one State, and, third, the competition with Colonel Felipe Santiago Salaverry to personify the true conservative revolution that would be the "savior of the country".

KeY words: State administration; patronage; conservative party; liberal party; Peru; XIX century; Agustín Gamarra; Felipe Santiago Salaverry. 